\title{
Evaluation of serum vitamin D levels in premenopausal women with iron deficiency anemia
}

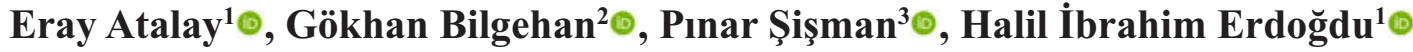 \\ ${ }^{1}$ Department of Internal Medicine, Kafkas University School of Medicine, Kars, Turkey \\ ${ }^{2}$ Department of Internal Medicine, Kulu State Hospital, Konya, Turkey \\ ${ }^{3}$ Department of Endocrinology and Metabolism, Medicana Hospital, Bursa, Turkey
}

\begin{abstract}
Objectives: In recent years, many effects of vitamin D except on bone metabolism have been discovered. Vitamin D contributes to the correction of the anemia by acting on the erythroid precursors in the bone marrow via Vitamin D Receptor and provides the elimination of free radicals and prooxidant substances secondary to iron deficiency due to its antioxidant effect in iron deficiency anemia (IDA).

Methods: A total of 97 female premenopausal women aged 18-44 were included in the study. Fifty patients with hemoglobin levels below $12 \mathrm{mg} / \mathrm{dl}$ and iron deficiency were classified as IDA group, and 47 subjects with hemoglobin levels of $12 \mathrm{mg} / \mathrm{dl}$ and above were classified as control group. The demographic data and biochemical parameters of all patients included in the study were analyzed.

Results: The vitamin D of the patient group was found to be $7.87 \pm 3.63 \mathrm{ng} / \mathrm{ml}$ and the vitamin $\mathrm{D}$ of the control group was $11.84 \pm 6.72 \mathrm{ng} / \mathrm{ml}$. The difference between the groups was statistically significant. There was a positive correlation between serum vitamin $\mathrm{D}$ and serum hemoglobin, hematocrit, serum $\mathrm{MCH}$, serum iron level, transferrin saturation index, ferritin.

Conclusions: In the light of the results of our study and other studies in the literature, we think that vitamin D deficiency may be important in patients with IDA and that vitamin D deficiency in these individuals will contribute to the regulation of anemia due to positive effects of vitamin D on both erythropoiesis and hepcidin in IDA are considered. However, larger studies are needed to clarify this issue.

Keywords: Vitamin D, iron deficiency anemia, anemia
\end{abstract}

I ron, is a vital element and essential for erythropoiesis, oxidative metabolism and cellular immune response. It has important functions in oxygen transport, catalysis of many enzymes in the energy system and the synthesis of deoxyribonucleic acid (DNA), ribonucleic acid (RNA) and protein $[1,2]$. As a result of cell metabolism, free radicals and reactive oxygen derivatives are formed. Free radicals show their effects on the cell membrane, organelles and DNA by causing protein, lipid, carbohydrate and DNA oxidation. These free radicals and reactive oxygen derivatives are neutralized by a complex antioxidant system [3]. It is accepted that oxidative stress increases in iron deficiency anemia (IDA) due to both increased oxidant amount and decreased antioxidant enzyme capacity [4]. The production of iron-containing proteins such as cytochrome, myoglobin, catalase and peroxidase is also affected in iron deficiency [5]. It has been shown in 
many studies that the activity of enzymes that protect cells against oxidative damage is impaired and thus tissues are exposed to oxidative stress in IDA [2].

In recent years, the determination of vitamin $\mathrm{D}$ receptor (VDR) in many tissues has revealed new opinions about the function of this vitamin. Many studies have shown the role of vitamin D deficiency in the formation of autoimmune diseases, inflammatory bowel disease, rheumatoid arthritis, multiple sclerosis, diabetes, infectious diseases, many types of cancer and heart diseases [6-8]. It was also determined modulator, antiinflammatory, antioxidant, antidiabetic, antihypertensive and renoprotective effectsof vitamine D [9]. Studies have shown that active vitamin D decreases proliferation and production of immunoglobulin [10] and affects erythropoiesis [11, 12]. Vitamin D levels are hundreds of times higher in the bone marrow compared to plasma and have been shown to be effective in regulating the functions of bone marrow. Red blood cells are prevented from becoming active in vitamin $\mathrm{D}$ deficiency [13]. It was also found to directly stimulate erythroid precursors [14]. Vitamin D, due to it's antioxidant and antiinflammatory effect, eliminate free radicals and prooxidant substances as well as through the VDR in the bone marrow contribute to the correction of anemia by acting on erythroid precursors. The aim of this study was to evaluate the effect of vitamin $\mathrm{D}$ levels on IDA in premenopausal women.

\section{METHODS}

A total of 97 female premenopausal women aged 18-44 were included in the study. Fifty patients with hemoglobin levels below $12 \mathrm{mg} / \mathrm{dl}$ and iron deficiency were classified as IDA group, and 47 subjects with hemoglobin levels of $12 \mathrm{mg} / \mathrm{dl}$ and above were classified as control group. Ethics Committee approval was obtained from the Ethics Committee of our center on 11.11.2015 and numbered 136. Exclusion criteria in our study; (i) detection of vitamin B12 or folic acid deficiency along with IDA, (ii) usage any iron preparation in the last 6 months before the study, (iii) presence of active infection, rheumatoid arthritis, ankylosing spondylitis, collagen tissue disease, celiac, hypo-hyperthyroidism, hypo-hyperparathyroidism, (iv) usage preparations such as calcium and vitamin D, bisphosphonates, calcitonin, selective estrogen receptor modulators, immunosuppressive drugs, antiepileptics, steroid, (v) presence of bone diseases, cushing syndrome, liver and kidney disease presence of malignancy, malnutrition and malabsorption. In the selection of individuals in the control group; the absence of any additional disease and the absence of IDAwas taken as the criterion. The demographic data and biochemical parameters of all patients included in the study were analyzed.

Complete blood counts were taken to tubes containing ethylenediaminetetraacetic acid (EDTA) and analyzed with Bt pro 2401. Serum AST, ALT, ALP, urea, creatinine, calcium, phosphorus, iron, total iron Binding Capacity (TIBC) levels were determined by the biochemistry analyzer Cobas 6000 C501 (Roche Diagnostics GmbH, Mannheim, Germany). Serum 25-Hydroxyvitamin D (25(OH)D), parathormone, vitamin B12, folic acid, ferritin levels were determined by Cobas e 411 (Roche Diagnostics GmbH, Mannheim, Germany).Body Mass Index (BMI); was calculated by dividing the weight of the patient by the square of his/her height $\left(\mathrm{kg} / \mathrm{m}^{2}\right)$ by using Quetlet index.

\section{Statistical Analysis}

Statistical analyzes were performed using SPSS 22.0 program (SPSS Inc. Chicago, IL). The normal distribution of the variables was tested by Kolmogorov smirnov and the variance equation was tested with the Levene test. Because of the normal distribution of the data, all analyzes were performed using parametric tests. Continuous variables were expressed as mean \pm standard deviation and categorical variables as percentage. IndependentSamples t-test was used for numerical variables and chi-square test was used for categorical ones. The relationship between vitamin D and other laboratory values was evaluated by Pearson correlation analysis. In the paired comparisons, the parameters which were statistically significant were included in the multivariate model. Stepwise logistic regression analysis was used to determine the independent risk factors of IDA. A receiver operator characteristic (ROC) curve was used to determine the cut-off value of vitamin D level for IDA. The area under the curve (AUC) was calculated for the accuracy of the test. A $p$ $<0.05$ was considered significant in all comparisons. 
Table 1. Demographic and laboratory datas of the groups

\begin{tabular}{lccc}
\hline Variables & $\begin{array}{c}\text { PatientGroup } \\
(\mathbf{n : ~ 5 0 )}\end{array}$ & $\begin{array}{c}\text { Control Group } \\
(\mathbf{n}: \mathbf{4 7})\end{array}$ & $\boldsymbol{p}$ value \\
\hline Age $($ years $)$ & $28.80 \pm 8.06$ & $28.27 \pm 6.53$ & 0.727 \\
\hline BMI $\left(\mathrm{kg} / \mathrm{m}^{2}\right)$ & $23.83 \pm 3.82$ & $23.64 \pm 3.12$ & 0.796 \\
\hline Hg $(\mathrm{gr} / \mathrm{dl})$ & $10.39 \pm 1.09$ & $14.06 \pm 0.65$ & $<\mathbf{0 . 0 0 1}$ \\
Hct $(\%)$ & $30.63 \pm 3.14$ & $41.33 \pm 2.13$ & $<\mathbf{0 , 0 0 1}$ \\
Iron $(\mu \mathrm{g} / \mathrm{dl})$ & $28.22 \pm 8.98$ & $104.02 \pm 30.8$ & $<\mathbf{0 . 0 0 1}$ \\
TIBC & $433.28 \pm 59.09$ & $352.43 \pm 52.61$ & $<\mathbf{0 . 0 0 1}$ \\
TSI $(\%)$ & $6.591 \pm 2.32$ & $29.98 \pm 9.61$ & $<\mathbf{0 , 0 0 1}$ \\
Ferritin $(\mathrm{ng} / \mathrm{ml})$ & $5.95 \pm 2.87$ & $36.88 \pm 17.93$ & $<\mathbf{0 . 0 0 1}$ \\
Vitamin D $(\mathrm{ng} / \mathrm{ml})$ & $7.87 \pm 3.63$ & $11.84 \pm 6.72$ & $\mathbf{0 . 0 1}$ \\
\hline
\end{tabular}

$\mathrm{BMI}=$ Body mass index, TSI $=$ Transferrin saturation index, $\mathrm{TIBC}=$ Total iron binding capacity

\section{RESULTS}

The mean age of the patients included in our study was $28.80 \pm 8.06$ years in the patient group and 28.27 \pm 6.33 years in the control group. There was no statistically significant difference between the groups $(p=0.727)$ (Table 1$)$. In the statistical analysis of vitamin D levels, the vitamin D level of the patient group was found to be $7.87 \pm 3.63 \mathrm{ng} / \mathrm{ml}$ and the vitamin D level of the control group was $11.84 \pm 6.72$ $\mathrm{ng} / \mathrm{ml}$. The difference between the groups was statistically significant ( $p=0.01$ ) (Fig. 1) (see Table $1)$.
In the statistical analysis, there was independent correlation between vitamin D level and IDA in logistic regression analysis $(B=1.168, p=0.02)$. The cut-off value of vitamin D level 9.12 was $74 \%$ sensitive and $40 \%$ specific for IDA. In the ROC curve analysis, the AUC value was $0.681(95 \% \mathrm{CI}=0.575$ $0.778, p<0.02$ ) (Fig. 2).

In our study, the correlation between serum vitamin D level and hemogram and iron parameters was found; There was a positive correlation between serum vitamin D level and serum hemoglobin level (r $=0.393, p<0.001)$ between serum vitamin $\mathrm{D}$ level and serum hematocrit level $(\mathrm{r}=0.419, p<0.001)$. And

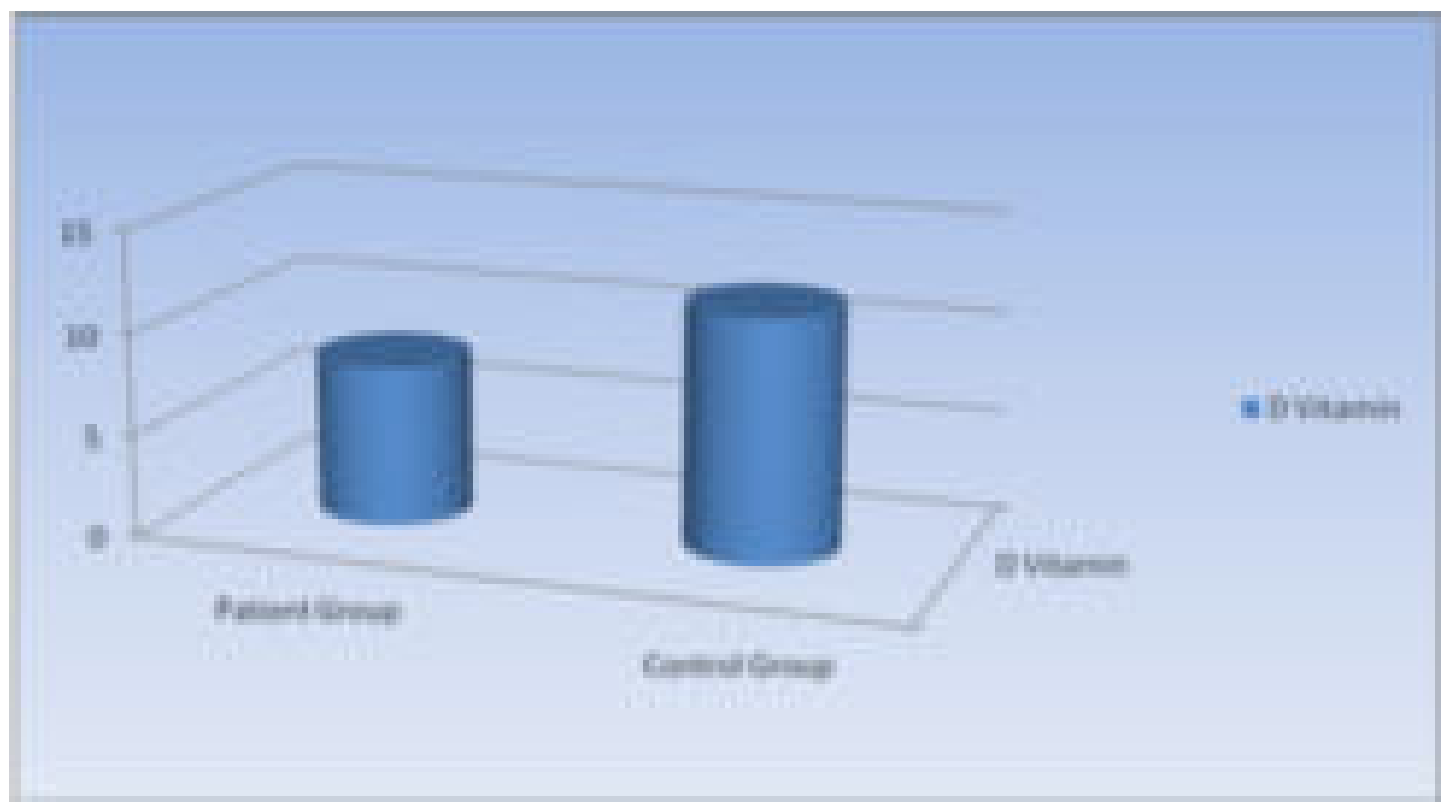

Fig. 1. Vitamin D levels of the groups. 


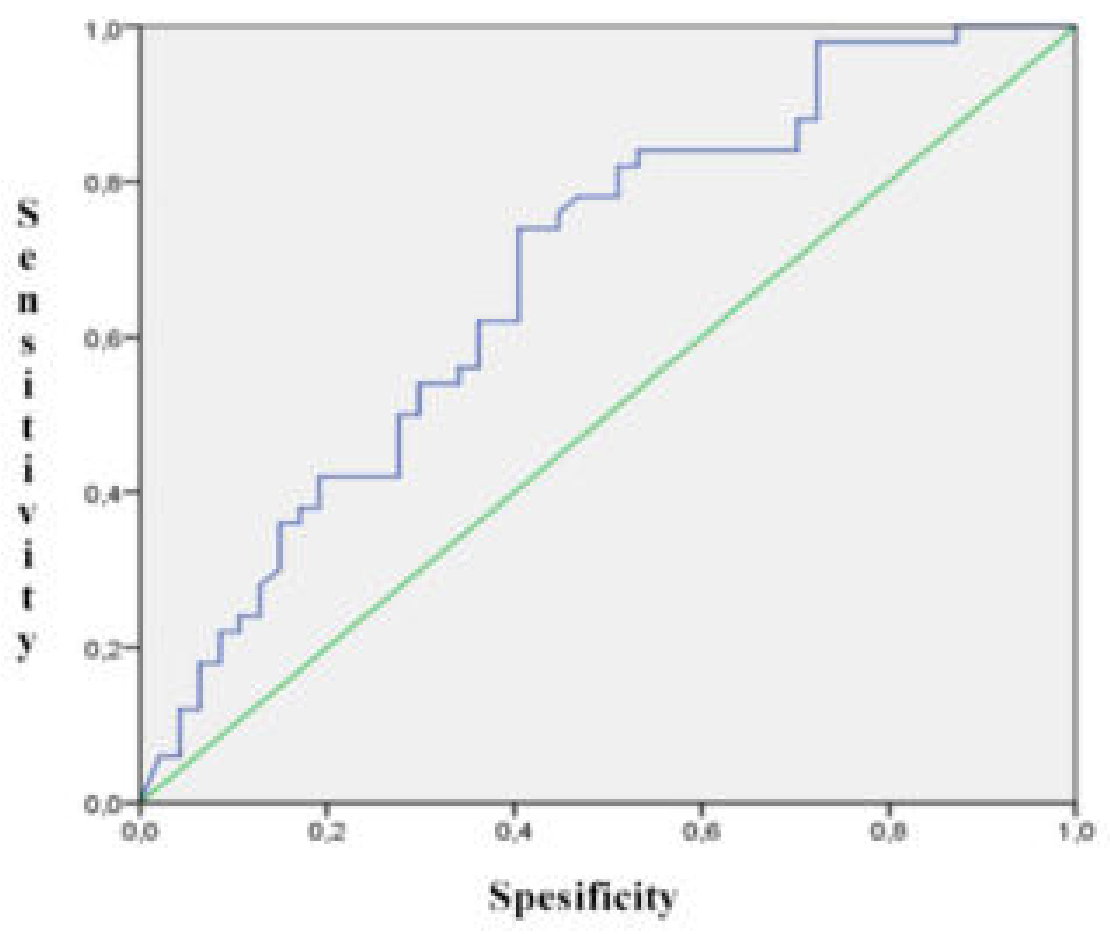

Fig. 2. Logistic regression graph of iron deficiency anemia parameters with vitamin D.

also positive correlation was found between serum vitamin $\mathrm{D}$ and serum $\mathrm{MCH}$ level $(\mathrm{r}=0.298, p=$ $0.003)$, serum iron level $(\mathrm{r}=0.301, \mathrm{p}=0.003)$, TSI ( $\mathrm{r}$ $=0.249, p=0,014)$, serum ferritin level $(\mathrm{r}=0.225, p$ $=0.026$ ). But there was a negative correlation between serum vitamin D level and serum RDW level $(r=$ $0,225, p=0.027)$.

\section{DISCUSSION}

Iron is an essential trace element for erythropoiesis, oxidative metabolism and cellular immune response, which has an effect on many systems $[2,15]$. In many studies, it has been suggested that IDA has effects on cellular functions, growth, motor and mental development, behavior and cognitive functions, immune system, gastrointestinal system and physical capacity [16]. The main task of erythrocytes is to carry oxygen. Erythrocytes, where oxidative events occur at any time, because they are constantly exposed to oxygen, are equipped with an extremely effective antioxidant defense system.

Unlike other cell types, there are many active antioxidant enzymes such as super oxide dismutase (SOD) and catalase. Decreased enzymatic antioxidant capacity of erythrocytes in IDA has been reported [1719]. Oxidative stress caused by the decrease in antioxidant enzyme activities in erythrocyte negatively affects oxidant/antioxidant system in serum. Serum antioxidant capacity cannot improve the increased oxidative state and result in increased oxidative stress [20]. In the study performed by Yoo et al. [21], oxidative capacity was significantly higher in the IDA group compared with the control group, and total antioxidant and catalase activity were found to be low. After four months of treatment, oxidant, antioxidant and catalase activity were found to be similar with control group [21].

Vitamin D has an immunomodulatory, antiinflammatory, antioxidant, antidiabetic, antihypertensive and renoprotective positive effects [9]. Active vitamin D has been reported to reduce the production of many inflammatory cytokines (IL-2, IL6 , IL-12, IFN-t1, TNF- $\alpha$, TNF- $\beta),[22]$, to cause cellular proliferation and to reduce the production of immunoglobulin [23].

Decreases in $25(\mathrm{OH}) \mathrm{D}$ levels may suppress erythropoiesis in bone marrow by decreasing local calcitriol production. Calcitriol has a direct proliferative effect on erythroid series cells. Endogenous erythropoietin and calcitriol have a 
synergistic effect. In addition, calcitriol upregulate erythropoietin receptors in erythroid progenitor cells $[24,25]$. In addition, calcitriol has a key role on the immune system and has an inhibitory effect on proinflammatory cytokine expression.Vitamin D is thought to be an inhibitory effect of anemia by its inhibitory effect on specific inflammatory pathways [26]. In the study conducted by Sim et al. [27], the probability of developing anemia was 1.86 times higher in people living in the south of the USA with vitamin $\mathrm{D}$ deficiency $(<30 \mathrm{ng} / \mathrm{ml})$. But there is no difference according to gender [27]. A total of 2,526 people were included in the study to investigate the relationship between vitamin D deficiency and IDA in Korean girls and boys and adolescents. It was found that the socioeconomic level of patients with IDA was lower, BMI was higher and vitamin D level was lower.As vitamin D levels increased, it was observed that IDA was less frequent but this difference was not found in men [28]. In another study, 158 pregnant women were included in the study. Vitamin D and iron levels were measured at the 25th and 40th weeks of gestation and the risk of IDA was found to be eight times higher in patients with vitamin D levels below $50 \mathrm{nmol} / 1$ [29]. Anemia that occurs in patients with vitamin D deficiency was previously attributed to the deficiency of erythropoietin production [30, 31]. However, recent studies also emphasize the role of hepcidin, a hepatic peptide [32]. Hepcidin is a systemic iron-regulating hormone. High plasma hepcidin levels lead to iron sequestration in macrophages, contributing to the pathogenesis of anemia by restricting the flow of iron into the erythropoietic bone marrow. Vitamin D deficiency was found to cause hepcidin upregulation [33].

In our study, the vitamin D levels were $7.87 \pm 3.63$ $\mathrm{ng} / \mathrm{ml}$ and $11.84 \pm 6.72 \mathrm{ng} / \mathrm{ml}$ in the IDA group and control group, respectively. There was a significant difference between the groups $(p=0.01)$. However, vitamin D level of both groups is deficient. Vitamin D deficiency in most of the participants shows that vitamin D deficiency is a public health problem in our country which should be taken seriously. One of the factors affecting the level of vitamin $\mathrm{D}$ is the degree of utilization of sunlight according to the latitude and longitude of the geographic region and also one of the personal factors affecting the vitamin D level is the style of clothing. Clothes constitute an important barrier between UV heat and skin [34]. The fact that most of the participants in our study have a closed clothing style may be another reason why vitamin D levels are so low.

\section{Limitations}

Our study has some restrictive aspects. In this cross-sectional, retrospective study, it is not possible to determine the exact pathophysiology of the relationship between vitamin D and IDA.The fact that hepcidin levels were not measured limit the explanation of the pathogenesis of anemia in patients.

\section{CONCLUSION}

In our study, although the serum vitamin D level of the patient group and the control group was below the reference value $(<20 \mathrm{ng} / \mathrm{ml})$, the difference between the groups was statistically significant ( $p=$ 0.01 ). There was a positive correlation between serum vitamin D level and serum hemoglobin, hematocrit, $\mathrm{MCV}, \mathrm{MCH}$, iron, transferrin saturation index, ferritin level, and negative correlation between serum RDW levels.

\section{Conflict of interest}

The authors disclosed no conflict of interest during the preparation or publication of this manuscript.

\section{Financing}

The authors disclosed that they did not receive any grant during conduction or writing of this study.

\section{Authors' Contribution}

All of the authors have contributed to the study on conception and design, drafting the article, revising it critically for important intellectual content, and final approval of the version to be published. All authors are in agreement with the content of the manuscript.

\section{REFERENCES}

1. Ganz T, Nemeth E. Iron imports. IV. Hepcidin and regulation of body iron metabolism. Am J Physiol Gastrointest Liver Physiol 2006;290:G199-203.

2. Oner AF, Bay A. [Iron deficiency anemia]. Türkiye Klinikleri 
J Pediatr Sci 2005;1:7-15. [Article in Turkish]

3. Diaz-Castro J, Alferez MJ, Lopez-Aliaga I, Nestares T, Granados S, Barrionuevo M, et al. Influence of nutritional iron deficiency anemia on DNA stability and lipid peroxidation in rats. Nutrition 2008;24:1167-73.

4. Aslan M, Horoz M, Kocyigit A, Ozgonul S, Celik H, Celik M, et al. Lymphocyte DNA damage and oxidative stress in patients with iron deficiency anemia. Mutat Res 2006;601:144-9.

5. Coghetto Baccin A, Lauerman Lazzaretti L, Duarte Martins Brandao V, Manfredini V, Peralba MC, Silveira Benfato M. Oxidative stress in older patients with iron deficiency anaemia. J Nutr Health Aging 2009;13:666-70.

6. Hollick MF. Sunlight and vitamin D for bone health and prevention of autoimmune diseases, cancer and cardiovascular disease. Am J ClinNutr 2004; 80 (6suppl): S1678-88.

7. Ward LM. Vitamin D deficiency in the 21 st century: a persistent problem among Canadian infants and mothers. CMAJ 2005;172:769-70.

8. Heaney RP. Long-latency deficiency disease: insights from calcium and vitamin D. Am J Clin Nutr 2003;78:912- 9.

9. Pilz S, Tomaschitz A, Drechsler C, de Boer RA. Vitamin D deficiency and heart disease. Kidney Int Suppl 2011;1:111-5.

10. Chen S, Sims GP, Chen XX, Gu YY, Chen S, Lipsky PE. Modulatory effect of 1,25 dihydroxyvitaminD3 on human B cell differentiation. J Immunol 2007;179:1634-47.

11. Blazsek I, Farabos C, Quittet P, Labat ML, Bringuier AF, Triana BK, et al. Bone marrow stromal cell defects and 1 alpha, 25-dihydroxyvitamin D3 deficiency underlying human myeloid leukemias. Cancer Detect Prev 1996;20:31-42.

12. Reichel H, Koeffler HP, Norman AW. The role of the vitamin $\mathrm{D}$ endocrine system in health and disease. N Engl J Med 1989;320:980-91.

13. Norman AW. Minireview: vitamin D receptor: new assignments for an already busy receptor. Endocrinology 2006; 147:5542-8.

14. Alon DB, Chaimovitz C, Dvilansky A, Lugassy G, Douvdevani A, Shany S, et al. Novel role of 1, $25(\mathrm{OH})(2) \mathrm{D}(3)$ in induction of erythroid progenitor cell proliferation. Exp Hematol 2002;30:403-9.

15. Lanzkowsky P. İron-deficiency anemia. Manual of Pediatric Hematology and Oncology 3rd ed., USA: Academic Press, 2000;33-47.

16. Prasad AN, Prasad C. Iron deficiency; non-hematological manifestations. Prog Food Nutr Sci 1991;15:255-83.

17. Ramakrishnan U, Aburto N, McCabe G, Martorell R. Multimicronutrient interventions but not vitamin A or iron interventions alone improve child growth: results of 3 metaanalyses. J Nutr 2004;134:2592-602.

18. Isler M, Delibas N, Guclu M, Gultekin F, Sutcu R, Bahceci M, Kosar A. Superoxide dismutase and glutathione peroxidase in erythrocytes of patients with iron deficiency anemia: effects of different modalities. Croat Med J 2002;43 16-9.
19. Vural H, Erel Ö, Koçyiğit A, Sabuncu T. [Oxidative stress in erythrocytes of patients with iron deficiency anemia]. Genel Tip Dergisi 1997;7:77-80. [Article in Turkish]

20. Kumerova A, Lece A, Skesters A, Silova A, Petuhovs V. Anaemia and antioxidant defence of the red blood cells. Mater Med Pol 1998;30:12-5.

21. Yoo JH, Maeng HY, Sun YK, Kim YA, Park DW, Park TS, et al. Oxidative status in iron-deficiency anemia. J Clin Lab Anal 2009;23:319-2.

22. İmazeki I, MatsuzakiJ, Tsuji $\mathrm{K}$, Nishimura $\mathrm{T}$. Immunomodulating effect of vitamin D3 derivaties on type-1 cellular immunity. Biomed Res 2006;27:1-9.

23. Modan M, Halkın H, Karasık A, Lusky A. Elevated serum uric acid: a facet of hyperinsulinemia. Diabetologia 1987;30:713-8.

24. Saab G, Young DO, Gincherman Y, Giles K, Norwood K, Coyne DW. Prevalence of vitamin D deficiency and the safety and effectiveness of monthly ergocalciferol in hemodialysis patients. Nephron Clin Pract 2007;105:c132-8.

25. Aucella F, Scalzulli RP, Gatta G, Vigilante M, Carella AM, Stallone C. Calcitriol increases burst-forming unit-erythroid proliferation in chronic renal failure. A synergistic effect with $\mathrm{r}$ HuEpo. Nephron Clin Pract 2003;95:c121-7.

26. Perlstein TS, Pande R, Berliner N, Vanasse GJ. Prevalence of 25-hydroxyvitamin D deficiency in subgroups of elderly persons with anemia: association with anemia of inflammation. Blood 2011;117:2800-6.

27. Sim JJ, Lac PT, Liu IL, Meguerditchian SO, Kumar VA, Kujubu DA, et al. Vitamin D deficiency and anemia: a crosssectional study. Ann Hematol 2010;89:447-52.

28. Lee JA, Hwang JS, Hwang IT, Kim DH, Seo J-H, Lim JS. Low vitamin D levels are associated with both iron deficiency and anemia in children and adolescents. Pediatr Hematol Oncol 2015;32:2:99-108.

29. Thomas CE, Guillet R, Queenan RA. Vitamin D status is inversely associated with anemia and serumerythropoietin during pregnancy. Am J Clin Nutr 2015;102:1088-95.

30. Meguro S, Tomita M, Katsuki T, Kato K, Oh H, Ainai A, et al. Plasma 25-hydroxyvitamin $\mathrm{d}$ is independently associated with hemoglobin concentration in male subjects with type 2 diabetes mellitus. Int J Endocrinol 2011;2011:362981.

31. Zittermann A, Jungvogel A, Prokop S, Kuhn J, Dreier J, Fuchs U, et al. Vitamin D deficiency is an independent predictor of anemia in end-stage heart failure. Clin Res Cardiol 2011;100:781-8.

32. Ganz T, Nemeth E. Hepcidin and iron homeostasis. Biochim Biophys Acta 2012;1823:1434-43.

33. Carvalho $\mathrm{C}$, Isakova $\mathrm{T}$, Collerone $\mathrm{G}$, et al. Hepcidin and disordered mineral metabolism in chronic kidney disease. Clin Nephrol 2011;76:90-8.

34. Holick MF. Vitamin D deficiency. N Engl J Med 2007;357:266-81. 